SHS Web of Conferences 6, 02009 (2014)

DOI: $10.1051 /$ shsconf / 20140602009

(C) Owned by the authors, published by EDP Sciences, 2014

\title{
The Transformation of the Cooperative Financial Mode in the Countryside of China and the Future Choice
}

\author{
Fu Qiong
}

The Finance School, Jilin University of Finance and Economics, 130112 Changchun Jilin, China

\begin{abstract}
As an important part of the financial system in the country, the cooperative finance for a long time is greatly promoted by the government to solve the problem of weak financial support in the countryside. For various reasons, it has not achieved many results, which reflects that only with government promotion it could not achieve success. Since 2003, some mutually-supported financial societies gradually gain the recognition from the government supervision agencies and gain a lawful status. However such cooperative agencies proceed very slowly with a lot of hindrance factors. Comparatively, some cooperative societies simultaneously organized by the peasants and some peasants' financial mutual supporting agencies become active and become an important way to solve temporary financial needs of the farmers in the process of production, which also provide a possible way for the integration of various sources in the countryside. Such modes have achieved success in Japan and Korea, although in China they remain in the state of research. We need to establish a suitable way of financial cooperative system for the countryside in China on the bases of experiences of other countries.
\end{abstract}

Keywords. rural cooperative finance; financial mutual support; professional cooperatives

\section{Introduction}

Financial cooperative is a kind of special form of endogenous financial organizations, which is formed in accordance with the concept and principle of cooperative. It basically raises the funds from the vulnerable group, and provides members with mutual financing. They are managed by the group members autonomously, and at their own risk. Cooperative finance has the obvious function in helping the disadvantages and poverty, which is quite different from commercial finance. It can also effectively avoid the defect of policy finance as "government failure". So from the experience of advanced countries, rural cooperative finance as well as commercial finance and policy finance is an important part of the financial system in the countryside.

During the past 30 years, the cooperative finance has been the main method of the government to break the supply-related constraints in Chinese rural finance. This constrains mainly resides in the insufficient network of official institutions and insufficient supply of funds by these institutions. But due to some reasons, China's rural cooperative financial organizations did not reflect the real connotation of the cooperation, even worse the majority of rural areas was in a state of absence. Therefore, it is necessary to discuss the development of sustainable rural cooperative financial mode under our national conditions. It is also the key point to improve the rural financial system and to promote the reform of the rural finance. 


\section{Development of rural cooperative financial organizations in China}

The reform of Chinese rural finance began with the rebuilding of cooperative system since China's reform and opening up. The study of cooperative finance has been concerned throughout the whole process during which the small and medium-sized financial institutions have rapidly grown up. The development of cooperative finance in China can be roughly divided into two clues, one is the reform of rural credit cooperatives, and the other is the establishment of new type of rural cooperative financial organizations. They both constitute the basic context of rural cooperative finance in China. The present rural cooperative financial system in China mainly includes rural credit cooperatives, rural cooperative Banks, financial mutual cooperatives, and some other unofficial financial organizations. But all these have big gap from the real cooperative financial organizations.

\subsection{The alienation of rural credit cooperatives}

The alienation of cooperative finance refers to that the cooperative financial organizations derive from the original principle of cooperatives in such aspects as structure, features and functions, etc. because of its internal conditions and external environment. From the establishment the rural credit cooperatives (RCCs) were once regarded as the main body of Chinese rural cooperative financial mode. As the main force in rural finance, RCCs have made clear about the cooperative reform direction since 1980, and eventually formed a "joint-stock bank" orientation. In 1996, rural credit cooperatives were separated from the administrative subordination relations of the Agricultural Bank of China (ABC), and gradually transform to institutions based on the principle of cooperative system. They were voluntarily invested, democratically managed by the members and provided them with mutual financing. In the next two years, RCCs were further back in the direction of "cooperative finance" on the property right structure. In 2003 RCCs have improved the corporate governance structure based on the separate legal entity, and according to the actual conditions have chosen the different form of ownership such as joint stock system, the joint stock cooperative system and cooperative system. In 2010, the China Banking Regulatory Commission (CBRC) was explicitly stipulated that the rural credit cooperatives can directly transform into rural commercial banks if were eligible, indicated the key link of RCCs reform has been achieved to the shareholding system. It was reported there were about 212 rural commercial banks and 90 rural cooperative banks countrywide.

The cooperative function alienation of RCCs mainly comes from its alienation of property right, and thus brings out a series of deviation of cooperative finance in business strategy, management methods, and service function. Theoretically, the property right of RCCs should belong to its members. But in practice, the right of ownership has been completely unable to embody because of the nature of "state-owned". That means the members of RCCs neither have the right of management supervision, nor the right of profit distribution. The member's congress, the board of directors and supervisors exist only in name. The obscure of property right directly brought about two problems, one is the insider control, and the other is the external intervention. In the pursuit of profit targets in the business strategy, RCCs gave up the rural market with high cost and risk, and turn to more profitable city market. The function of mutual assistance between the members was weakening, and more credit flew to the private or township enterprises with higher marginal revenue. Thus comparing to the basic principles of cooperative finance-voluntary, cooperation, mutual assistance, and democratic management- RCCs in our country is out of the scope of cooperative finance. Look from the practice of rural credit cooperatives in recent years, the effect of joint-stock system reform has emerged. Its governance structure, management level, profit ability and risk control ability were all improved significantly. Predictably, if this reform all goes well, there we will set up a wide coverage and a perfect rural commercial finance system. But this will further cause the lack of cooperative finance in vast countryside. Most farmers cannot enjoy the benefit of cooperative finance, and vulnerable groups will continue to face financial constraints due to the high threshold with the commercial finance.

\subsection{The failure of rural cooperative fund association}


Rural cooperative fund associations (RCFA) were established driven by the government in the 1980's in the process of implementation of household-responsibility system, in order to avoid the loss of rural collective assets. They were a kind of cooperative financial organizations by the initial nature. Part of the fund is from cleaning up the collective assets left over by history, and the other part is invested by farmers voluntarily. Rural cooperative fund association to some extent satisfied the farmers' increasing demand released by the transformation of system, and stimulated the farmers' willingness of investment. Also they changed the situation that the capital flow in single direction from the rural area to the city and reduced the capital constraints of rural economic development. But Lack of effective supervision and meddling from local governments led to their closure in 1999.

The rural cooperative fund associations came from the capital demand for agricultural producing in rural society, as well as the deficiency of financial service of our current rural financial system. Although failed, this rural cooperative financial practice provided the beneficial guidance and experience for reference. Many domestic scholars have studies on the issue. Wen tiejun (2007) pointed out that because of the ownership of the funds did not belong to farmers or the village collective, but to the local governments, the intervention by the local governments led to a large number of non-performing loans in the fund associations.

From the experience of RCFAs, we can conclude that cooperative finance is absolutely necessary for the farmers to obtain financial resources. But if such financial institutions are not born in the farmer's demand, while established by the government's promotion, they are bound to fail for the defect of insider's control and external intervene.

\subsection{The rise of new types of rural financial cooperative organizations}

The path dependence of rural credit cooperatives' reform has become apparent; it seems that they cannot be transformed to the cooperative financial organizations now. As the government allows the rural land circulation and agriculture develops in the direction of intensification, professional cooperative society gradually becomes a new economic form in the rural areas after entering the $21 \mathrm{st}$ century. Organized agricultural production mode inspired farmers' financial demands. In some areas, members of professional cooperative societies carry out spontaneously fund mutual behaviors. This form of financial cooperation in some areas has evolved into specialized organization of financial mutual support. In March of 2003, the first fund mutual cooperative was set up in Yanjia village, Jilin province. From then on, this new type of rural organizations gradually developed, opening up a new round of rural cooperative finance practice in China. In addition, some mutual funds supported by foreign cooperative funds, social activists and poverty reduction support program under a certain financial support also began in parts of the pilot.

These pilots were confirmed to the reform goals of trying to establish a multi-level and variety in rural financial system by the government. In 2006 the central no. 1 files clearly put forward " to guide farmers to establish fund mutual cooperatives", and in Dec.2006, CBRC issued document that "it could guide private capital to participate in village and town banks, micro-finance organization and fund mutual cooperative". These new types of rural financial institutions were officially legal. From one statistic, that by the end of June 2012, there were 49 rural fund mutual cooperatives approved by the regulatory authority of CBRC. In addition, there are more than 5000 of unofficial rural fund mutual cooperatives. Compared with the government cautiously promotion, spontaneous established organizations of mutual support have already been a certain scale, marked the rural cooperative finance in China is developing fast.

These attempts compared with past practice, highlight the principle of cooperation and mutual assistance, focus on farmer's cooperative ability, and minimize the state and local government intervention, which embody the connotation of cooperative finance.

\section{Analysis of present mode of Chinese rural cooperative finance}


For the nature of the rural credit cooperatives and rural cooperative Banks, at present there is a big debate, part of the view consider that it is still the mainstream form of rural cooperative finance in China, but most view consider that these organizations are more like commercial finance. So we think the main mode of current rural cooperative finance is all kinds of new type of rural fund mutual cooperatives. These financial organizations basically have the following categories:

\subsection{Official rural fund mutual cooperatives}

Such institutions refer to the mutual financial banking institutions with independent enterprise legal person qualification. These institutions are supervised, inspected and approved by CBRC, invested by farmers of certain rural areas and rural small enterprise, and provide members with deposits, loans, settlement and other business. It must meet the requirements of the banking regulatory departments, and its business operation shall be subject to supervision of the banking regulatory and supervision departments at all levels, meanwhile can also enjoy the implicit deposit insurance provided by the regulators.

\subsection{Non-official rural fund mutual cooperatives}

Such organizations are born from the professional cooperatives with no formal quotations, but alone engaged in the financial mutual support business. They are approved by the local government departments, and registered in the local industrial and commercial bureaus. Actually they are just the professional cooperatives but have the independent departments to engage in funds mutual support. This kind of organizations does not have regulatory approval, no financial license, also can not be classified as formal financial sequence. But they tend to have a sound constitution and organization structure and has relatively stable economic ties between members. They are regulated by local governments; therefore have the obvious difference with the traditional folk financial organizations. These organizations can be seen as professional cooperatives in funds, and the umbers are far more than the formal quotation of rural fund mutual cooperatives.

\subsection{Financial mutual support within the professional cooperatives}

Under this kind of mode, there is no separate department in the professional cooperatives; the members will support each other with funds whenever they need. The members undertake the financial mutual support with the funds accumulated in the process of marketing and other professional cooperation, and as productive cooperation scale expand, the more accumulation can be used to support each other. Along with the development and expansion of professional cooperatives, this form of cooperative finance has a huge space for development.

\subsection{The non-profit and poverty alleviation funds mutual cooperation mode}

This kind of funds mutual cooperatives is usually invested by the national finance capital, activists, individual person etc. and guide farmers to gradually participate in. Its form is more loosely, and is a kind of experimental group. They are not strictly cooperative financial organizations.

\section{The problems existing in the official rural fund mutual cooperatives}

The above four kinds of mutually-supported financial societies fully reflects the connotation of cooperative finance, meets the diversified financial demand of peasants and with good cooperation foundation. We looked further into these cooperatives then found out that mutually-supported financial cooperatives for the poverty have the policy orientation obviously. The remains can be divided into two groups; one is originated in the background that lack of formal financial supply and 
pushed by the governments which we called the new cooperative organization exclusively engaged in mutually-supported financial services under the framework of CBRC. The other is completely endogenous from all kinds of farmer's professional cooperatives. That is, a fund mutual cooperative based on the demand of mutual support and formed in the process of producing-supplying-selling cooperation.

The farmers' fund mutual cooperatives under the framework of CBRC, though, are different from the past cooperative finance organizations like rural credit cooperatives or rural cooperative funds. They ate authentic, formal and existing outside of the formal financial system arrangements in China (He Wenguang, 2007). However, since 2006 the practice shows that there are many problems in terms of the actual operation and regulatory and also existing a certain gap in connection to the basic principle of cooperative finance.

\subsection{Organization and operation pattern tends to formal commercial finance-the new tendency of dissimilation}

In 2007, CBRC position the fund mutual cooperatives as "a community mutual banking financial institution with independent legal person qualification". Therefore, the regulation and supervision of them just resemble that of the formal banking financial institutions, so that it enforce higher request on personnel, funds, business premises and applications. It will increase the operating cost of fund mutual cooperatives on the condition that these institutions are operated under the frame work of the legal person system. It will also lead to decreasing the marginal revenue of the institutions and cannot cover the operating cost in some smaller scale of mutually-supported financial service. For the above reason, on one hand, some of the institutions taking high rate deposits to expand their sources of funding. On the other hand, the resulting adverse selection will make the loan applied to higher earnings SMEs(small and medium enterprises), the large farmer-households and so on. Such operations not only deviate from the connotation of mutual financial support, but also create additional financial risks. Regulatory with the intention of controlling risks strictly also reduce the flexibility of mutuallysupported financial services and frustrate the enthusiasm of farmers to develop such organizations. Through our research for the fund mutual cooperatives in Lishu County, Jilin Province, some of the loan rate of such institutions even higher than the commercial finance in the same grade. This phenomenon leads to losing the advantage of cooperative finance. In fact, advantages of rural mutual cooperatives are endogenous within its rural economy, information symmetry, lower capital cost, flexible and convenient loans and better meet the needs of farmers for microfinance. The conclusion is that the fund mutual cooperatives will lose their advantages if operate like formal financial institutions.

\subsection{The slow development due to the cautions regulation and supervision concept}

The government put forward policy to encourage the development of rural fund mutual cooperatives and farmers have the practical financial needs. But in practice, the progress is very little for the fund mutual cooperatives got the approval of CBRC. By June 2012, there are only 49 such institutions in the countrywide, lag far behind most of the spontaneous practice of rural cooperative finance. The reason is mainly related to the cautions regularity policy of our supervision department. To a kind of new organization form, the reason that regularity authorities enforce strictly supervision mainly refers to the perspective of risk prevention, specifically on the condition that the farmers' lack of financial knowledge, the weakness of risk awareness, the insufficiency of democratic management experience and the poorness of self-protection ability. Therefore we need more external regulation to standardize management and protect the interests of these vulnerable groups. There is no deposit insurance mechanism in our rural cooperative financial organizations in China now. Once these institutions are taken control under the framework of the CBRC, that means they can get invisible government guarantee. So as an insurer's perspective, supervisory authorities must be strictly supervised. However the reality is that regulators are confined by its own resources and they cannot afford to take effective regulatory responsibilities. Thus, although the government enforce many policies from the national 
level in order to support the development of fund mutual cooperatives, the implementation of region regulatory authorities is not active, which leading to the slowly development of these institutions under the framework of the CBRC.

\subsection{The lack of supervision in the actual operation leads to significant risk}

The slow development of fund mutual cooperatives is due to the cautions regulation policy of the supervision authorities. While the local government with the encouragement of central policy, take a more positive attitude to the fund mutual cooperatives and give legitimacy of the establishment of the institutions. Although such institutions have not got official license, their business scope and operation mode are not distinctive from official fund mutual cooperatives. They are usually supervised by the certain local government departments. These regulatory body lack experience with the supervision of the financial institutions and their responsibilities is not clear among the regulatory departments. The unofficial fund mutual cooperatives, in fact, are in the condition of inadequate supervision. Such institutions can finance from society and they are not supervised by the CBRC and conformed to the rules that "fund mutual cooperatives can only absorb deposits from their membership and financing from official commercial financial institutions". Some unofficial fund mutual cooperatives grow rapidly but also pose a huge risk. In 2012, four fund mutual cooperatives had irregular operations and capital chain rupture, which fully revealed the potential risk of such institutions.

\subsection{The competitive disadvantage arose from business overlap with other rural financial institutions}

One of the benefits of cooperative finance is that it is rooted in the countryside, based on kinship and geographical relation. So they obtain the members' behaviors, habits, demand statuses, personality characteristics and operation schedule information more accurately. Thus they can provide further financial services close to the farmer's demand. The lower transaction cost is also one of the core competitiveness of fund mutual cooperatives. But many official rural fund mutual cooperatives, in order to expand access to higher loan scale and income, they prefer to compete with other rural financial institutions for the "high quality customers". But because of their deficiencies, these institutions are more likely to get higher transaction costs than regular banks. Both on the side of deposits and loans, rural fund mutual cooperatives do not have enough competitive advantage and their cognitive degree for farmers is inefficient too.

\section{Conclusions - the future choice of Chinese rural cooperative finance}

The practice of Chinese cooperative finance in the countryside was the outcome of compulsory institutional change promoted by the government, which belonged to the exogenous type. Since 2006, the development of fund mutual cooperatives which promoted by the CBRC, has got the obvious characteristics of endogenous change. And the actual development of rural fund mutual cooperatives has been seriously impeded. The previous practice shows that the Chinese rural cooperative finance can not completely solve the problem of function alienation. However, to a certain degree that the rural cooperative finance are different from other parts of financial system, it can not be achieved by the government's mandatory system changes. So we should gradually develop and improve the farmers' independent consciousness and management ability from the basic principles of cooperative finance and the rural economic reality. That is the only way to develop the endogenous type rural cooperative financial organizations.

The official fund mutual cooperatives and unofficial ones promoted by the local government proceed very slowly and bear prodigious risk. Comparatively, the mutual-support business based on the professional farmers' cooperatives is well developed. According to the data from one research undertaken by the People's Bank of China in 2009, the number of the funds mutual departments relying on professional farmers cooperatives accounted for $51 \%$ of the total number of institutions. 
The number of the unofficial funds mutual cooperatives organized by the farmers accounted for $25 \%$. Those which established with the approval of the CBRC only accounted for less than $1 \%$. From the point of the perspective of loan funds scale view, the number of the mutual funds departments accounted for $53 \%$ of the total number of institutions. We can conclude the endogenous type mutually-supported financial organizations are the main form of rural cooperative finance.

The endogenous type financial cooperatives are developed in the process of farmers' production. Due to the expansion of production scale and funds demand, the formal commercial finance cannot meet that farmers' demand. From the practice in Japan, South Korea and China's Taiwan, these regions all have adopted this cooperative finance model. And the degree of alienation is very low. These countries have gained quite successful experience. Based on the reference of the experiences abroad, we should promote the credit cooperation in professional farmers' cooperatives, to establish some endogenous cooperative financial organizations.

Based on the common production cooperation, the endogenous cooperative financial organizations will easily gain members' acceptance. Based on the relationship between "acquaintance societies", the stable economic ties of the members guarantee that the cooperative finance function is not prone to alienation. As long as assisting with the government's policy guidance, the endogenous cooperative financial organizations can become the main mode of Chinese rural cooperative finance, which can effectively solve the problem of the lack of financial resources in rural areas. Moreover, the natural advantages of the endogenous cooperative financial organizations also determine the broad space for their development. Those advantages include low organizational risk, low transaction cost and more wholesale financing from the large financial institutions etc. According to the experience of Japan, the union among endogenous cooperative financial organizations will form a new cooperative financial system which has wide coverage area and strong anti-risk ability. Of course, the healthy development of endogenous cooperative financial model still needs the guidance of government policy and the specification of relevant laws and regulations. So the government should formulate and improve the relevant legislation and regulations as soon as possible, establish a clear regulatory system, give finance and tax policy support, to promote the endogenous cooperative financial organizations' reasonable development, and play the role of finance in rural economic growth.

\section{References}

1. Sun Shizhong. "Deciphering the reform dilemma: equity changes and governance reconstruction of rural small and medium-sized financial institutions "[C]. CBRC Working Paper, 2012.3.

2. Sheng Xuejun, Yu Chaoyin. "The legal system of refractory of China's rural cooperative finance" [J].The Social Sciences, 2010(12).

3. Deyuan Zhang, Yajun Zhang. "The analysis of farmer capital mutual cooperation organization" [J]. The Economists, 2008(1).

4. Wangbin. "China's rural cooperative financial function alienation and reconstruction" [J]. Economics and Economic Management, 2008(2)

5. Peng Keqiang. "The stock of rural cooperative financial reform and incremental development" [J]. Journal of Beijing University of Science and Technology, 2007(4).

6. He Wenguang. "The rural funds cooperation mechanism of and its performance "[J]. The Financial Theory and Practice, 2007(4).

7. Zhou Li. "Why do we need to mutual funds - the experience of 10 rural cooperatives" [J].Agriculture, Rural Areas and Farmers in China, 2006(1).

8. Hayek, "The Constitution of Liberty", London and Chicago,1960, p.59.

9. Ning Xia. "The rural financial cooperation and innovation Since the reform and opening up" [J]. Journal of huazhong agricultural university, 2011(2)

10. Wen Tiejun. "Return the cooperative finance to farmers" [J].Rural 